\title{
AN ANALYSIS ON USAGE PREFERENCES OF LEARNING OBJECTS AND LEARNING OBJECT REPOSITORIES AMONG PRE-SERVICE TEACHERS
}

\author{
Res. Assist. Sabiha YENI \\ Yıldız Technical University \\ Department of Computer Education \\ \& Instructional Technologies \\ Istanbul, TURKEY \\ Assoc. Prof. Dr. Nesrin OZDENER \\ Marmara University \\ Department of Computer Education \\ \& Instructional Technologies \\ Istanbul, TURKEY
}

\section{ABSTRACT}

The purpose of the study is to investigate how pre-service teachers benefit from learning objects repositories while preparing course content. Qualitative and quantitative data collection methods were used in a mixed methods approach. This study was carried out with 74 teachers from the Faculty of Education. In the first phase of the study, pre-service teachers' prior knowledge about learning objects was defined. During the second phase of the study, a two-hour seminar was given to pre-service teachers to introduce the learning objects and the object repositories. Then, they were requested to prepare a course content and instructional plan using the object repositories. During the last phase of the study, their opinions about the object approach were determined. According to findings; before the seminar, it was observed that pre-services teachers didn't know learning objects and object repositories. Also, they didn't use learning object repositories as a reference for their courses. Pre-service teachers' preferences about learning object repositories were change according to some different factors: especially language, interaction level and resource type.

Furthermore, it was seen that most of them exhibited positive attitude toward learning objects. As a conclusion, it would be worthwhile to increase the number of object repositories allowing preparation of course contents by combining objects to form a whole, in order to promote and spread use of learning object approach among teachers and preservice teachers through in-service training and pre-service training programs. Also, considering the factors affecting selection of learning objects, it would be an important step to provide support to creation of object repositories particularly in the native language, with high explanatory quality and exercise opportunities, for development and spread of use of learning objects and repositories.

Keywords: Web-based Learning, Learning Objects, Learning Object Repositories, Content Development. 


\section{INTRODUCTION}

Advancements in the information and communication technologies have led to considerable changes in design and development of instructional materials, and in making them available to learners. One of the important links of these changes is the Learning Object, which is an instructional technology that will provide guidance for next generation of applications with its reusability, adaptability, scalability and productivity potentials (Day,2001; Cakıroğlu, 2007; Karaman, 2005). The IEEE (Institute of Electrical and Electronics Engineers) LTSC (Learning Technology Standards Committee) workgroup defined the learning object as a digital or non-digital entity that can be used or referenced for many times during technology-supported learning. Wiley (2000) defined learning objects as resources that are reusable to support learning.

Today, advancements in the instructional technologies have led to changes in learning styles of students as well. Traditional learning environments have become attuned to the development of distance learning. Online curricula have started to be created due to increasing population, expanding geographic areas, and economic factors.

The need for obtaining low-cost, high-quality materials and information online through the web has made the way to the learning object concept. Learning objects are e-learning contents that are prepared for distance education and run in learning repositories. Therefore, students and teachers, as well as organizations organizing educational programs, can be enabled to reap the advantages offered by distance training utilizing the learning objects designed effectively. It is important that administrators, teachers and students are aware of the learning object approach, so that, along with the technological opportunities gradually becoming more and more widespread at educational institutions, the potential benefits of use of technology can be maximized. Permanent and studentcentered learning environments, in which students can structure their own learning, can be created using the online learning object approach.

In this context, emphasis can be placed on promotion of the learning object approach, and spreading its in-class applications. Teachers can be provided with on-the-job training on creation, selection of learning objects, and integration of the same to classroom applications.

Furthermore, in addition to the training that would enable teachers to see examples of applications and websites, decisions can be made on joint activities and teachers can be convinced to take online courses on the subject.

As the educational institutions, teachers and students tend towards reusable learning objects, teaching designers will have to change their traditional teaching design habits for transition into teaching designs based on learning objects. To this end, high quality and effective designs can be developed by identifying the key factors in object and object repository preferences of teachers and students to increase proficiency of learning objects and object repositories.

Consequently, studies to be conducted on learning objects, which become more and more valuable in the world, will offer alternatives for preparation of different course environments, while providing contributions to individual learning by offering them to the service of students, and assisting them to create their own information. 
This study aims to determine the extent the pre-service teachers make use of the object repositories, and how they use them in preparation of course contents. The study also investigates the factors affecting pre-service teachers' selection of teaching objects within the object repositories after the relevant training, in the context of type of source, level of interaction, and language factor.

\section{SEARCH PROBLEMS}

Answers to the following research problems were sought within the scope of this study:

$>$ What is the situation of pre-service teachers' use of the digital sources and object repositories found on the Internet or other environments?

$>$ How do preferences of pre-service teachers differ by object repositories in the native language and in foreign languages?

$>$ How do the objects used by pre-service teachers differ by interaction level?

$>$ How do the objects used by pre-service teachers differ by type of source (text, still images, animations, etc)?

$>$ What are the factors affecting pre-service teachers' preference of objects?

$>$ What are the factors affecting pre-service teachers' preference of object repositories?

$>$ What are pre-service teachers' opinions about the object approach and object repositories?

$>$ What are pre-service teachers' opinions about the restrictions of the object repositories?

\section{LITERATURE}

Distance education is a type of formal training, in which many education functions are implemented in an environment, where the instructors and students are away from each other (Verduin and Clark, 1991). E-learning is an educational activity that can be performed by way of Internet technologies, without the requirement for teachers and students to be in the same environment at the same time (Mutlu et al., 2004). Students can access the courses at any time, without time restrictions. Teachers can provide academic consultancy to students, and find solutions to their problems swiftly. They can use a number of communication facilities such as e-mail, chat rooms, etc. for this purpose. For an effective learning activity, an e-learning material should contain components such as text, sound, simple graphical presentations, video presentations, animations, simulations, games, testing systems, and interactions supported with feedbacks, etc. (Cakıroğlu \& Baki, 2006). One of the tools that enable effective presentation of learning contents created on these environments is the learning objects.

\section{What is a Learning Object?}

Even though the philosophy and origins of the learning objects are quite clear, not only the descriptions, but also the designations show differences. It is generally accepted that they can be reused once they are prepared (Millar, 2002). IEEE (Institute of Electrical and Electronics Engineers) LTSC (Learning Technology Standards Committee) workgroup's Learning Technology Standard Committee, which conducts researches on learning technologies, defines the learning groups as "any entity, digital or non-digital, that can be used, reused or referenced during technology-supported learning". Wiley (2000) defined learning objects as "resources that are reusable to support learning". 
Macromedia (2002), a software company, defines learning objects as "each one of the modular pieces of contents used in educational and learning applications". DLNET (Digital Library Network for Engineering and Technology) initiative defines the learning objects as "structured resources containing high-quality information so as to facilitate learning and teaching". According to Robson (2000), learning objects are expected to have the following characteristics:

$>$ Each chunk should be able to communicate with the educational systems using a standardized method that does not depend on the system,

$>$ What happens within a chunk is the chunk's business,

$>$ How a learner moves between chunks is controlled by the learning system,

$>$ Each chunk must have a description that enables designers to search for and find the right chunk for the right job. Each of these chunks is called "learning objects".

If learning objects are prepared effectively, they provide many facilities to students, teachers and learning organizations. Permanent learning, student-centred learning, learning by doing, etc., which are emphasized frequently particularly by educators today, will be possible only if such objects are prepared effectively (Cakıroğlu, 2007).

\section{Integration of Learning Objects into Learning Environments}

According to Ilomaki et al (2003), place and use of the learning objects within some learning/teaching activities are as follows:

\section{Activate Prior Knowledge}

Learning objects may help students to check their familiarity with the subject being learned, and to see the restrictions of their existing knowledge. They may contain thoughtprovoking questions, and videos, images, animations or texts that show the situations contradicting their existing knowledge. Support conceptual change: Learning objects may be used for different applications in the form of inducing the pre-knowledge of students, forcing their existing frame of mind, allowing them to express themselves and to interact with the content, and presenting the content using different presentations and in relation to each other. Give possibility to face the complexity of the content: Learning objects can be prepared as objects that consist of real problems, contain real-life situations, and particularly include different solutions to problems.

\section{Give Multiple Representations}

Learning objects comprising of the same contents in different formats (text, image, video, etc.) can be prepared.

\section{Social Interaction}

Objects containing tasks requiring cooperative activities such as preparation of school bulletin boards and research tasks, etc. can be prepared.

\section{Visualization of Thinking}

Learning objects containing different problem situations and context, objects that would enable students to see the relations among different examples, and simulations with high level of interaction, with which students would be able to apply different solutions, can be prepared. 
Skill Training

Exercise objects that focus on one or more skills, allow adjustment of the number of repetitions and difficulty level, and provide feedbacks based on user performance can be used.

\section{Learning Object Repositories}

Learning Objects Repository is, in its simplest definition, "is a content storage system for learning objects" (ADLCOLAB, 2001, Cebeci, 2003). Academic institutions and professional organizations all around the world put forth considerable efforts to enable network resources and databases to reach the learning environments. One of the ways preferred for this purpose is to open the learning resources to the use of students and teachers by way of learning object repositories (Porter et al, 2002). Learning object repositories have emerged since the mid-1990s to assist instructors to find and select the learning objects (Williams, 2000). According to Advisory Committee for Online Learning (ACOL) (2001), "learning objects repository is a collection of learning/teaching materials allowing online access to the courses offered by a number of institutions".

\section{Integration of the Object Repositories into the Learning Environments}

The Internet has become one of the best research tools for teachers. However, even the strongest search engine like Google returns many results rather than the required ones for specific search term. This situation makes it difficult to find and identify the high quality learning sources. In this context, learning object repositories facilitates access to the learning objects (Richard et al, 2003). Object repositories provide contents for the learning environments. It can be said that the repositories facilitate learning and teaching in terms of the following (Duncan, 2003):

Quality

Thanks to a large learning objects pool, instructors spend less time to prepare new objects, for they do not have to prepare the same things again. Quality of teaching increases, for instructors will have more time to arrange the teaching activities (Duncan, 2003).

\section{Productivity}

Thanks to object repositories, it is quite easy to create a new object by adapting an existing one (Duncan, 2003). Object repositories provide time and labour savings in sharing and use of materials (Richard et al, 2003).

\section{Diversity}

Because object management systems are independent from the types of learning objects, they do not impose any restrictions when uploading the objects. Consequently, users that will make use of a specific repository can find a great variety of objects that can be used in different environments. Learning object repositories encourage instructors to develop a work approach containing the culture of managing, sharing and reusing the objects effectively (Duncan, 2003).

\section{METHODOLOGY}

Designed as a case study, one of the qualitative research designs, this study was conducted with 74 pre-service teachers studying at Faculty of Education Department of Elementary Mathematics Teaching. 
Qualitative and quantitative data collection methods were used in a mixed methods approach during the process. During the first phase of the study, the pre-service teachers' status of use of digital resources on the Internet or other environments was measured by using the "Material Development and Utilization Scale" (Karaman, 2005).

Furthermore, pre-service teachers' status of use of object repositories and their preknowledge about the learning objects were measured using the "Object Repository Use Questionnaire". During the second phase of the study, a two-hour seminar was given to pre-service teachers to introduce the learning objects and the object repositories.

Then, they were requested to prepare a 40-minute course content and instructional plan using the object repositories. Pre-service teachers were allowed one week to prepare the course content and the instructional plan.

They were requested to use the "Course Content Preparation Questionnaire" to determine the reasons of their preference of objects and object repositories they used during this phase. During the last phase of the study, their opinions about the object approach and object repositories were determined using the "Application Evaluation Questionnaire", while pre-service teachers were delivering the course contents after one week. Results of the questionnaires given before and after the application, and of the document analyses performed with the instructional plans were utilized in answering the research questions.

\section{FINDINGS}

Findings are presented under headings specified based on the research problems.

What is the situation of pre-service teachers' use of the digital sources and object repositories found on the Internet or other environments? Data provided in Table 1 show that 42 pre-service teachers $(56 \%)$ made use of the Internet sources to prepare course contents, and that 73 pre-service teachers $(98 \%)$ were not aware of the learning objects. None of the pre-service teachers used the object repositories.

Table: 1

Teachers' and pre-service teachers' situation of use of the Internet sources, learning objects and object repositories

\begin{tabular}{|c|c|c|c|c|}
\hline \multirow[t]{2}{*}{ Group $(n=74)$} & \multicolumn{2}{|c|}{ Yes } & \multicolumn{2}{|c|}{ No } \\
\hline & f & $\%$ & f & $\%$ \\
\hline $\begin{array}{l}\text { I use the Internet sources to prepare a presentation or course content. } \\
\text { I use the learning objects to prepare a presentation or course content. } \\
\text { I use the object repositories to prepare a presentation or course content. }\end{array}$ & $\begin{array}{c}42 \\
1 \\
0\end{array}$ & $\begin{array}{c}56.7 \\
1.4 \\
0\end{array}$ & $\begin{array}{l}32 \\
73 \\
74\end{array}$ & $\begin{array}{l}43.3 \\
98.6 \\
100\end{array}$ \\
\hline
\end{tabular}

Pre-service teachers were provided with a list of purposes of their use of computers personally, and asked for what purposes they considered to use the information technologies (Table 2).

66 pre-service teachers $(89 \%)$ stated they used the information technologies to obtain information and materials for teaching. Furthermore, it was found that pre-service teachers were rather reluctant $(50 \%)$ to use devices such as scanners, etc. to prepare for lessons, and to share materials on the web environment. 
Table: 2

Pre-service teachers' purposes of use of the information technologies $(n=74)$

\begin{tabular}{lcccc}
\hline Objectives & Yes & \multicolumn{2}{c}{ No } \\
\hline Obtaining information and materials from the Internet & $\mathbf{f}$ & $\%$ & $\mathbf{f}$ & $\%$ \\
Preparation of course notes & 66 & 89.2 & $\mathbf{8}$ & 10.8 \\
Recording and calculating the scores of students & 62 & 83.8 & 12 & 16.2 \\
Preparation of instructional plans & 58 & 78.4 & 16 & 21.6 \\
Communicating with others & 56 & 75.7 & 18 & 24.3 \\
Assignment of tasks, provision of resources or opinions via web & 54 & 73 & 20 & 27 \\
Sharing files with other teachers & 51 & 68.9 & 23 & 31.1 \\
Use of web cameras, digital cameras or scanners for & 41 & 55.4 & 33 & 44.6 \\
preparing for lessons & 37 & 50 & 37 & 50 \\
\hline
\end{tabular}

With reference to the use of Internet sources and materials, the order of priority of the major types of resources needed by pre-service teachers was determined (Figure 1).

It was found that pre-service teachers gave priority to materials in the form of simulations and videos, while they used materials in the form of text and tutorial less.

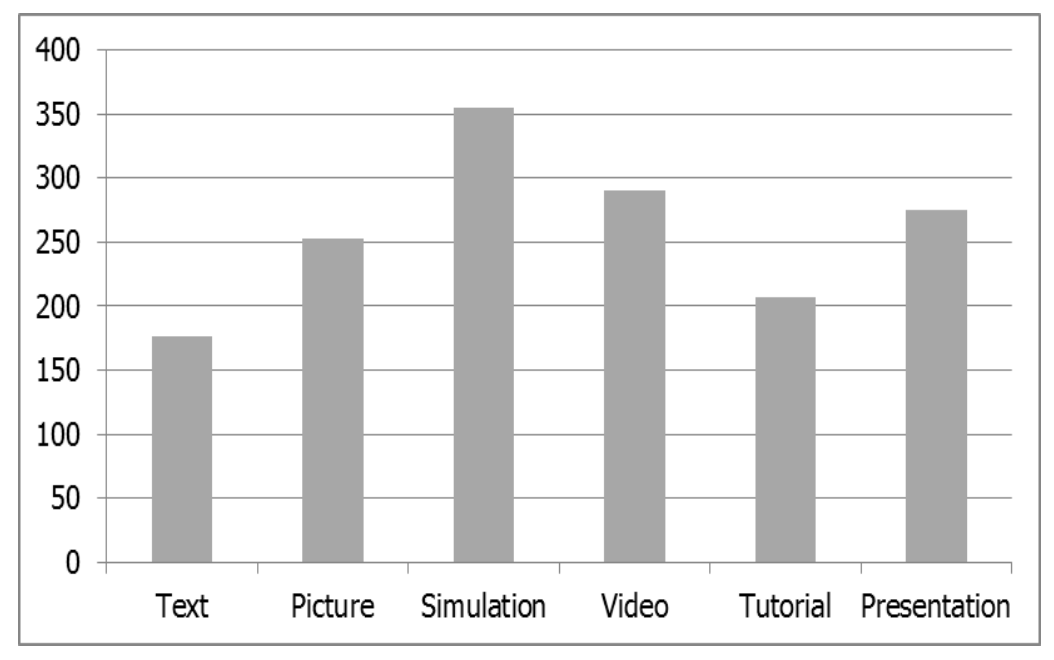

Figure: 1

Totals of priority scores of pre-service teachers' utilization of Internet sources

It is important to determine the challenges faced by pre-service teachers, who will encounter the learning object approach for the first time, in preparing the course contents with the traditional approach, in order to determine their existing situations. The challenges faced by pre-service teachers in preparation of course materials are provided in

Table 3. Accordingly, it can be said that they mostly encountered problems with shapes that distort when they are copied and pasted $(X=3)$.

The fact that competency of use of devices such as scanners, etc. while preparing course materials is rather low $(X=2.4)$ also draws attention. 
Table: 3

Challenges faced by pre-service teachers while preparing course materials

(min: 1, max:5)

Statements

I have difficulties in finding Turkish materials when obtaining content from the Internet.

I have difficulties in making modifications on the materials I download from the Internet.

I have difficulties in creating meaningful materials, when I bring together the materials I

download from the Internet.

I spend a lot of time to access the resources on the Internet.

I have difficulties in searching materials using key words in foreign languages, due to my

lack of English language skills.

I have troubles with copy/paste operations, particularly when fonts fail, while I use the

sources on the Internet for my course.

I have troubles with copy/paste operations, particularly when shapes distort, while I use the sources on the Internet for my course.

I can use scanner to prepare computer-aided materials.

\section{How Do Preferences of Pre-Service Teachers Differ}

by Object Repositories in the Native Language and in Foreign Languages?

Following a seminar given to pre-service teachers to introduce the learning objects and object repositories, they were requested to prepare a 40-minute course content and instructional plan using the object repositories. Pre-service teachers used total of 330 learning objects. 281 learning objects (85\%) were in the native language, while $49(15 \%)$ were in foreign languages (Table 4). Another finding related to impact of language factor on selection of objects was obtained from the "Application Evaluation Scale". $54 \%$ of the pre-service teachers stated they had trouble in using the object repositories in foreign languages, while $31 \%$ stated they did not experience any difficulties. $15 \%$ of the preservice teachers were undecided.

Table: 4

Opinions relating to objects and object repositories in foreign languages

\begin{tabular}{lc}
\hline Distribution of used objects by language factor & $\%$ \\
\hline Native language & $\mathbf{8 5}$ \\
Foreign language & 15 \\
\hline Influence of language factor on selection of objects & $\%$ \\
\hline I had difficulties in using the object repositories in foreign language. & 54 \\
I did not have difficulties in using the object repositories in foreign language & 31 \\
\hline
\end{tabular}

How Do the Objects Used by Pre-Service Teachers Differ by Interaction Level?

The interaction levels of the objects used by pre-service teachers in preparing course contents were investigated. The extent of users to intervene in functioning of objects is considered the level of interaction. The levels were divided into five categories by the researcher: very low, low, medium, high, and very high. Accordingly, out of total 330 learning objects used, 112 objects (34\%) were found to be at the low level, $35(10 \%)$ at the medium level, $42(13 \%)$ at the high level, and $24(7 \%)$ at the very high level. It can be seen that the interaction levels of objects are generally at low levels. The objects in the form of texts and tutorials were mostly used while preparing the contents. It was seen that pre-service teachers mainly preferred the non-interactive and verbal objects. 
How Do the Objects Used by Pre-Service Teachers Differ

by Type of Source (Text, Images, Animations, etc.)?

Pre-service teachers were asked to specify the type of source for each object they used while preparing course contents. Accordingly, they used different types of sources such as texts, tutorials, animations, simulations, drills, pictures and videos, etc.

When the distribution of total of $\mathbf{3 3 0}$ objects used by type of source, it was seen that $\mathbf{7 0}$ objects $(21 \%)$ were in the form of text, $68(20 \%)$ in the form of tutorial, $59(18 \%)$ in the form of animation, $52(15 \%)$ in the form of simulation, $49(14 \%)$ in the form of drills, 24 $(7 \%)$ in the form of pictures, and $8(2 \%)$ in the form of video.

The types of sources that were used most were texts and tutorials, while those that were used least were pictures and videos. When considered together with the graph provided in Figure 1, it was seen that, even though pre-service teachers had stated they mostly used simulation and video sources, they mainly used texts and tutorials while preparing course contents.

What Are the Factors Affecting Pre-Service Teachers' Preference of Objects?

Pre-service teachers were requested to specify the reasons why they preferred an object they used in preparing course contents.

Accordingly, as can be seen in Table 5, the most important reason for preference was the explanatory quality of the learning object $(29.8 \%)$, while the least important reasons for preference were the file size $(4.6 \%)$ and audio/visual quality $(5.8)$ of the objects.

Table: 5

Factors affecting preference of objects

\begin{tabular}{lc}
\hline Statements & $\%$ \\
\hline Object has high explanatory quality & 29.8 \\
Object is in the native language & 21.4 \\
Object provides the opportunity to do exercises & 18.9 \\
Object is interactive & 18.5 \\
High audio/visual quality, have difficulties in searching & 5.8 \\
Small file size & 4.6 \\
Other (Enjoyable, suitable for level of students, etc.) & 1 \\
\hline
\end{tabular}

What are the factors affecting pre-service teachers' preference of object repositories? Pre-service teachers were requested to specify the object repository, from which they obtained the object they used, while preparing course contents.

The pre-service teachers were given the web-addresses of object repositories such as Atanesa, Learnalberta, Egitim.gov and Skoool as examples. Out of total of $\mathbf{3 3 0}$ learning objects used, $198(60 \%)$ were obtained from Atanesa, $49(15 \%)$ from Learnalberta, 47 (14\%) from Egitim.com, and $36(60 \%)$ from Skoool object repositories.

Another finding related to the object repositories was: pre-service teachers were requested to rate each object repository they used between 1 (worst) and 4 (best). According to Figure 2, the most favored object repository was Atanesa (256) and the least favored one was Learnalberta (150). 


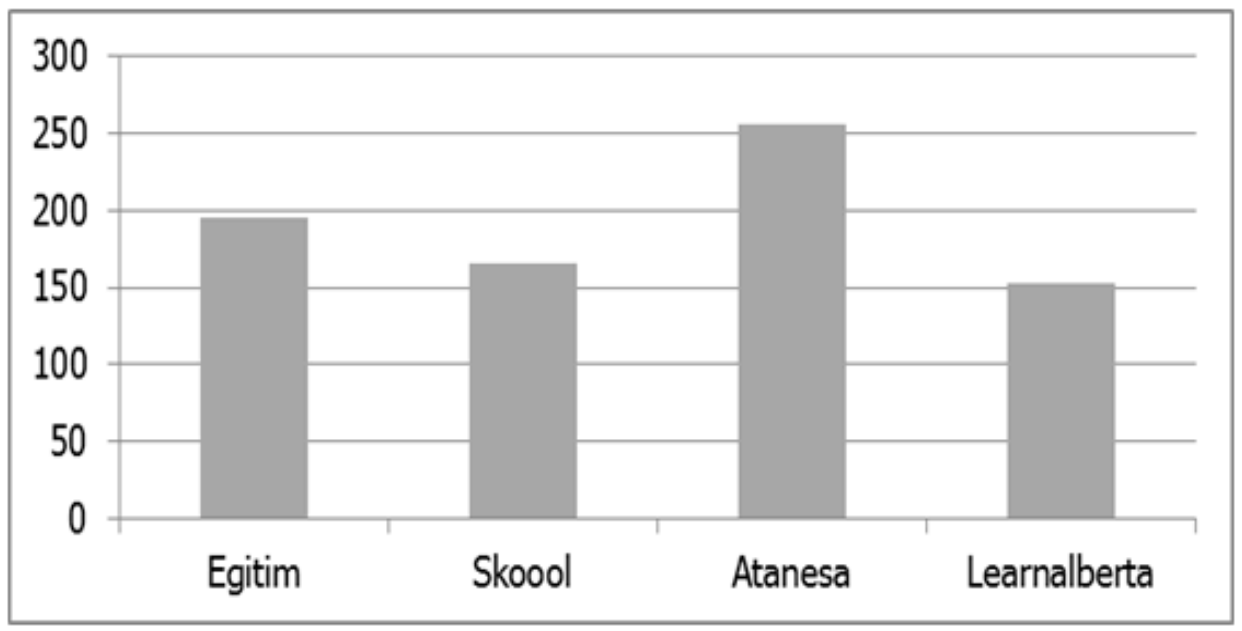

Figure: 2

Overall score totals of object repositories

According to Table 6, the most important factor in high preference rates of Egitim.gov.tr $(45.2 \%)$ and Skoool $(41.3 \%)$ was that they are in the native language of the pre-service teachers. Characteristics such as number of objects, convenience of downloading objects, object search tools, etc., were mainly not given as reasons for preference of these websites. A similar distribution can be seen among percentages of factors affecting preference of the Atanesa object repository.

This similarity explains why Atanesa was the most favored object repository, as can be seen in Figure 2. High number of objects $(22.6 \%)$ and provision of search function (22.6\%) were more effective in preference compared to other factors in Atanesa object repository. As for Learnalberta, high number of objects $(31.8 \%)$ and high object quality $(27.3 \%)$ were the most important factors in preference of this object repository.

Table: 6

Factors affecting preference of object repositories (\%)

\begin{tabular}{lcccc}
\hline \multicolumn{1}{c}{ Statements } & Egitim & Skoool & Atanesa & Learnalberta \\
\hline In native language/ foreign language & 45.2 & 41.3 & 21.2 & 11.4 \\
Contains high number of objects related to & 14.2 & 10.3 & 22.6 & 31.8 \\
subjects & & & & \\
High object quality & 21.7 & 20.7 & 15.6 & 27.3 \\
Object search facility & 9.4 & 13.8 & 22.6 & 20.5 \\
Object download convenience & 7.5 & 9.2 & 18 & 5.7 \\
Other & 1.9 & 4.6 & 0 & 3.4 \\
\hline
\end{tabular}

What Are the Pre-Service Teachers' Opinions

About the Object Approach and Object Repositories?

Following the application, approaches of pre-service teachers towards learning objects and object repositories were investigated. Percentage of pre-service teachers, who participated in the seminar on learning objects and object repositories and in the 
application, as well as those who want to receive training to create objects relating to subjects and add the objects they created to the object repositories after the application was $84 \%(\mathrm{~N}=62)$ (agree and strongly agree). $9 \%(\mathrm{~N}=7)$ of the pre-service teachers that participated in the application (strongly disagree and disagree) do not agree that it was necessary. Opinions of pre-service teachers related to learning objects and object repositories are as follows:

"Because mathematics is an abstract concept, we need to concretize it as far as possible to make students sense it with their senses to learn better. In

this context, object repositories can be very beneficial [01]. We can use motivating, eye-catching objects that assist students to enjoy learning, and that combine real world applications with mathematics well, in our lessons [02]. It takes a little time, but they can assist students visually to learn. If we can find objects that may appeal to students, we can help them to like the subject and the course [03]. It would provide facilities in learning. It is advantageous in terms of teachers as well [04]. They have benefits, but they take considerable time; and it is difficult to find original objects in the

Turkish language [05]."

What Are the Pre-Service Teachers' Opinions

About the Restrictions of the Object Repositories?

Pre-service teachers were asked an open-ended question related to the problems they encountered while using object repositories. Responses were classified using descriptive analysis method, and findings are provided in Table 7. Accordingly, it was seen that preservice teachers experienced most problems in three basic points such as "existence of object download option (23.9\%)", "number of subjects and objects (21.7\%)", "existence of a search engine to find specific objects in the repository $(21.7 \%)$ ".

Table: 7

Problems encountered while using object repositories

\begin{tabular}{lc}
\hline Statement & $\%$ \\
\hline Lack of object download option in some repositories & 23.9 \\
Insufficiency of the existing subjects and low number of objects & 21.7 \\
Lack of search engine in some repositories & 21.7 \\
Problems in using object repositories in foreign languages & 13 \\
Problems in finding high quality objects & 8 \\
Nonexistence indication of grade of objects & 2.9 \\
Nonconformity of the foreign object repositories with the curriculum & 2.2 \\
Combining objects to form a whole & 2.2 \\
Low number of object repositories & 1.4 \\
Too difficult and complicated to use & 1.4 \\
Loss of time & 1.4 \\
\hline
\end{tabular}

\section{CONCLUSION}

Pre-service teachers have sufficient level of knowledge of and positive attitude towards use of Internet sources. Even though pre-service teachers have considerably high rate of use of Internet sources for lessons, it is seen that they do not know about learning objects and the object repositories, and that they do not use the object repositories as a reference source for preparing the course contents. 
After the seminar, when the objects used during application were examined, it was seen that number of objects in foreign languages were extremely low, and that mostly the objects in the native language were preferred. Furthermore, most of the pre-service teachers stated they had difficulties in use of object repositories in foreign languages.

This situation emphasizes the importance of provision of language education at faculties of education. It was seen that pre-service teachers give priority to simulation and video materials, which have high visual quality and interaction levels, when they use the Internet sources. However, after the course content development application, it was seen that they used the text and tutorial types of sources more.

Furthermore, the most important factors affecting preference of objects for pre-service teachers were explanatory quality of the learning object, learning objects in the native language, and provision of opportunity to do exercises.

It was seen that pre-service teachers obtained a large portion of the objects they used in preparing course contents were obtained from Atanesa object repository, which was followed by Learnalberta, Egitim and Skoool object repositories respectively.

With reference to the factors affecting preference of repositories, the most important factors for the Egitim and Skoool object repositories were that they provide services in the native language, and offer access to high number of high-quality learning objects. High number of learning objects offered and provision of search functionality are the factors that positively affect preference of the Atanesa repository compared to the other factors.

In the light of the above, it can be concluded that importance should be attached to offer an advanced object search function, high number of subjects and objects, and high-quality audio/visual objects.

When the opinions of the pre-service teachers relating to object approach and object repositories were investigated, it was seen that most of them had positive attitude towards the same. Beyond using the already existing objects, most of the participants wanted to receive training on creating objects and adding them to repositories.

Consequently, it would be worthwhile to increase the number of object repositories allowing preparation of course contents by combining objects to form a whole, in order to promote and spread use of learning object approach among teachers and pre-service teachers through in-service training and pre-service training programs.

Thus, it would be easier for teachers and students to find high quality educational contents related to subjects at any levels, without having to perform searches on the Internet.

Considering the factors affecting selection of learning objects, it would be an important step to provide support to creation of object repositories particularly in the native language, with high explanatory quality and exercise opportunities, for development and spread of use of learning objects and repositories. Paying attention to factors such as offering high number of subjects and relevant objects, provision of advanced search options, etc. is important to make teachers and students to consider object repositories as a source of reference. 


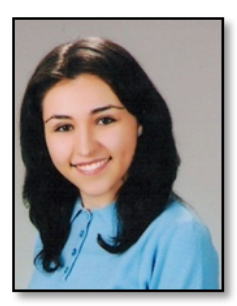

Sabiha YENI is a research assistant at the Faculty of Education in Yildiz Technical University. She received her BA from Marmara University in Computer and Instructional Technologies and her MA from the same department. She is now PhD student at Middle East Technical University in the Computer Education and Instructional Technology Department. Her main interests are human computer interaction and usability of educational software.

Yıldız Technical University,

Faculty of Education, Department of Computer and

Instructional Technologies Istanbul, TURKEY

Phone: +(90) 2123834842

Email: sabihaakgun@gmail.com

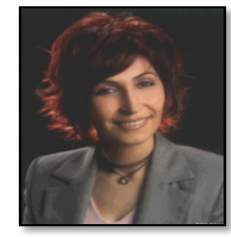

Nesrin OZDENER is associate professor at the Atatürk Faculty of Education at the University of Marmara. In 2001 she recived the PH.D. grade in Physics at Marmara University. She has been teaching at Computer and Instructional Technologies Department since 1998. Her main research interest concerns, teaching programming languages, educational software design and simulations.

Marmara University, Atatürk Faculty of Education, Department of Computer and Instructional Technologies, Istanbul, TURKEY

Phone: +(90) 2163454705 ext: 315

Email: nozdener@marmara.edu.tr

\section{REFERENCES}

ACOL (Advisory Committee for Online Learning) (2001). Strategies for stimulating the online education system in Canada. Retrieved on February 12, 2009 from

http://mlggam.ic.gc.ca/sites/acolccael/en/resources/R01_Anderson_Downes/rp_12.asp

Cebeci, Z. (2003). Öğrenim Nesnesi Ambarlarına Giriş [Introduction to Learning Object Repositories]. Electronic Journal of Social Sciences, 2 (2), (1-6).

Cakıroglu, U. \& Baki, A. (2006). E-Öğrenme Ortamları için Tekrar Kullanılabilir Öğrenme Nesneleri Tasarımı [Reusable Learning Objects Design for E-Learning Environments], XI. Türkiye'de Internet Konferansı, Ankara, Turkey.

Cakıroglu, U. (2007). Web tabanlı eğitim içeriği geliştirmede nesneye dayalı programlama kullanımı [The use of object-oriented programming in developing Web-based educational content], XII. Elektrik, Elektronik, Bilgisayar ve Biyomedikal Mühendisliği Ulusal Kongresi ve Fuarı, Eskisehir, Turkey.

Day, M. (2001), UK integrating Metadata Schema Registries with Digital Preservation Systems to Support Interoperability: a Proposal, Retrieved on January 23, 2009 from http://www.siderean.com/dc2003/101_paper38.pdf 
DLNET (2001), Brief Introduction to Learning Objects in DLNET, Retrieved on January 13, 2009 from http://www.dlnet.vt.edu/working_docs/reports/ARI_LO_Def.pdf

Duncan, C. (2003). The Value of Managing Learning Objects, An Intrallect White Paper, Intrallect Ltd.

Ilomaki, L., Jaakkola, T., Lakka1a, M., Nirhamo, L., Nurmi, S., Paavola, S., Rahikainen, M., \& Lehtinen, E. (2003). Principles, Models and Examples for Designing Learning Objects (LOs). Pedagogical Guidelines in CELEBRATE. A Working Paper for the European Commission, CELEBRATE Project, IST-2001-35188.

Karaman, S. (2005). Developıng a Learnıng Object Based Content Development System and Determınıng the Object Based Content Design Profiles of Pre-Service Teachers. PhD Thesis, Atatürk University, Institute of Social Sciences, Erzurum, Turkey.

Macromedia (2002), Creating Learning Objects for Your Organization, Learning Objects Development Center, Retrieved on July 05, 2012 from http://www.adobe.com/resources/elearning/whitepapers.html

Millar, G. (2002). Learning Objects 101: A Primer for Neophytes, Learning Resources Unit, British Columbia Institute of Technology, Retrieved on January 8, 2009 from http://online.bcit.ca/sidebars/02november/inside-out-1.htm

Mutlu, M. E. Dincer, G. Okur, M. R. , Sisman S. (2004). Öğrenim Sistemlerinin Tasarımında Kavram Haritaları, Öğrenme Nesneleri ve Eğitim Yönetim Sistemlerinin Rolü [The Role of Concept Maps, Learning Objects and Learning Management Systems in the Design of Learning Systems], Akademik Bilişim 04, Trabzon, Turkey.

Porter D., Curry J., Muirhead B. \& Galan N. (2002). A Report on Learning Object Repositories. Retrieved on February 04, 2009 from http://www.canarie.ca/funding/learning/lor.pdf

Richards, G., McGreal, R., Hatala, M. \& Friesen, N. (2003). The Evolution of Learning Object Repository Technologies: Portals for On-line Objects for Learning, Journal of Distance Education, Special Issue on Learning Object Repositories.

Robson, R. (2000). "All About Learning Objects'. Eduworks Corporation. Retrieved on November 15, 2009 from http://www.eduworks.com/LOTT/tutorial/learningobjects.html

Verduin, J. R, Clark, T. A. (1991). Distance Education: The Foundations of Effective Practice. California: Jossey - Bass Publisher.

Wiley, D. A. (2000). Connecting Learning Objects to instructional Design Theory: Definition, a Metaphor, and a Taxonomy. In D. Wiley (Ed.), The Instructional Use of Learning Objects. Retrieved on January 12, 2009 from http://reusability.org/read

Williams, D. D. (2000). Evaluation of Learning Objects and Instruction Using Learning Objects. In D. Wiley (Ed.), The Instructional Use of Learning Objects. Retrieved on January 12, 2009 from http://reusability.org/read 